\title{
Growth, delayed fluorescence and pigment composition of four Prorocentrum minimum strains growing at two salinities
}

\author{
MAJA BERDEN-ZRIMEC ${ }^{1}$, VESNA FLANDER-PUTRLE ${ }^{2}$, LUKA DRINOVEC $^{1}$, \\ ALEXIS ZRIMEC $^{1}$ and MARINA MONTI ${ }^{3}$
}

\author{
${ }^{1}$ Institute of Physical Biology, Veliko Mlacevo 59, SI-1290 Grosuplje, Slovenia \\ ${ }^{2}$ Marine Biology Station Piran, NIB, Fornace 41, SI-6330 Piran, Slovenia \\ ${ }^{3}$ OGS, Biological Oceanography Dept., Via Auguste Piccard 54, I-34014, Trieste, Italy
}

\begin{abstract}
Prorocentrum minimum is a potentially harmful and widely distributed marine dinoflagellate. Several $P$. minimum strains have already been studied, showing phylogenetical relations of strains isolated from the same geographical regions. Similarity among the strains was further examined on the basis of their physiology. Pigment composition and concentration, as well as delayed fluorescence (DF) decay kinetics and intensity, were measured in four P. minimum strains isolated from the Baltic and Adriatic Seas. The strains were grown at two salinities characteristic of the Baltic (8 PSU) and North Adriatic Seas (32 PSU). Strain differences in DF decay kinetics and growth did not always follow their genetic relations. While two strains showed similarities to the previously described strains from the Baltic and Adriatic Seas in DF parameters, the other two strains seemed to be specific. The differences among strains isolated from the same sea could stem from adaptations to conditions in the specific habitats. Cluster analysis based on the ratio of individual carotenoid pigments concentrations to the chlorophyll $a$ concentration or to total carotenoids were not conclusive in showing relations among the strains. Among the measured pigments, only peridinin concentration depended on salinity in all strains.
\end{abstract}

Key terms: Adriatic Sea, Baltic Sea, delayed fluorescence, HPLC, Prorocentrum minimum, strains.

\section{INTRODUCTION}

Prorocentrum minimum (Pavillard) Schiller is a cosmopolitan bloom-forming marine dinoflagellate living in coastal and brackish waters of tropical, subtropical and temperate climates (Heil et al., 2005). Its wide distribution is enabled by great physiological flexibility and the ability to utilize both inorganic and organic nitrogen, phosphorus, and carbon nutrient sources (Heil et al., 2005). P. minimum is a eurythermal and euryhaline species that can grow over a broad salinity range (2-35 PSU, Heil et al., 2005), but prefers salinity between 15 and 35 PSU (Tyler and Seliger, 1981; Grzebyk and Berland, 1996). $P$. minimum capacity for adaptation to various environments and conditions is reflected in a number of strains isolated from several geographical regions. $P$. minimum is an important phytoplankton species because it can produce harmful blooms (Grzebyk et al., 1997; Denardou-Queneherve et al., 1999; Heil et al., 2005). It can be toxic to humans via ingestion of shellfish containing hepatotoxic or neurotoxic substances, which can kill mice within minutes (Heil et al., 2005). Its strains have different potentials for producing toxins (Denardou et al., 1995; Grzebyk et al., 1997), which makes their research valuable for understanding P. minimum ecology.

Algal strains can differ in morphology (Heil et al., 2005) as well as in physiology and genetics, even when collected from 
geographically proximate locations (Gomez and Gonzalez, 2005). Physiology of photosynthesis can vary among strains. Strains differences can affect pigment content (Zapata et al., 2004), and consequently, pigment concentrations within taxa may vary regionally. The research of three $P$. minimum strains from different geographical areas (Monti et al., 2005) showed that they exhibit different delayed fluorescence decay kinetics and growth rates when cultured under the same laboratory conditions.

Delayed fluorescence (DF) is a longlived light emission from photosynthetic organisms after being illuminated with light and put into darkness (Strehler and Arnold, 1951). DF has the same emission spectrum as chlorophyll $a(\mathrm{Chl} a)$ fluorescence, but occurs with a time delay (from milliseconds to minutes) (Arnold and Davidson, 1954; Van Wijk et al., 1999). DF originates from repopulation of excited states of chlorophyll from stored energy after charge separation (Joliot et al., 1971). It has hyperbolic decay kinetics during the first seconds, which are sometimes followed by a more or less pronounced peak (Bertsch, 1962; Desai et al., 1983; Hideg et al., 1991; Zrimec et al., 2005). DF decay kinetics can differ among taxa (Zrimec et al., 2005) and even among strains (Monti et al., 2005), because the entire entity of photosynthetic apparatus is involved in its emission. DF intensity (DFI) represents the integral under the decay curve and is an increasing function of the number of PSII centers, the fluorescence yield and the rate of back reactions, which are influenced by the membrane potential and $\mathrm{pH}$ gradient (Joliot et al., 1971; Wraight and Crofts, 1971; Avron and Schreiber, 1979; Joliot and Joliot, 1980). DFI can be used as a measure of living algal biomass and has already been compared to HPLC measurements of Chl $a$ concentrations, indicating that correlation of parameters was related to the type of environment (Wiltshire et al., 1998).

Dinoflagellates possess four major photosynthetic pigments: chlorophyll $a$, chlorophyll $c_{2}$, diadinoxanthin and peridinin (Jeffrey and Mantoura, 1997). Peridinin is the principal photoreceptor for photosynthesis in $P$. minimum (Prezelin and
Haxo, 1976). Most of the flexibility in the pigment system of $P$. minimum in response to changes of spectral quality and irradiance is attributable to fluctuating concentrations of chlorophyll $a$, chlorophyll $c$, peridinin, and minor carotenoids (Faust et al., 1982).

In this research, the physiology of four $P$. minimum strains isolated from two geographical regions was compared. The four strains presented here and the three other $P$. minimum strains, previously described by Monti et al. (2005) were genetically characterized and phylogenetically divided into three groups (Monti, 2007) showing similarity of strains isolated from the same geographical region (the Baltic Sea, the Adriatic Sea and the Chesapeake Bay, USA). When comparing two previously described

$P$. minimum strains from the Adriatic $(\mathrm{PmK})$ and Baltic (BAL) Seas, distinct differences in growth and DF decay kinetics between them were observed (Monti et al., 2005). Due to the genetically established relation of the strains isolated from the same geographical regions, the differences in photosynthetic parameters and culture growth of four additional strains from the Baltic and Adriatic Seas were researched using DF and HPLC measurements at two salinities characteristic for the Baltic ( 8 PSU) and North Adriatic Seas (32 PSU).

\section{METHODS}

\section{Algal strains}

Two $P$. minimum strains were isolated from different areas of the Baltic (SWE and FIN) and two from the North Adriatic Seas (MAR and RAV) (Table I).

\section{Culture conditions}

The stock cultures were maintained at the Biological Oceanography Department of the National Institute of Oceanography and Experimental Geophysics (Trieste, Italy) under cool-white fluorescent light $(14: 10 \mathrm{~h}$ light:dark cycle, the average $30 \mu \mathrm{mol} \mathrm{m} \mathrm{m}^{-2} \mathrm{~s}^{-1}$ $\mathrm{PAR})$ at $15^{\circ} \mathrm{C}$. They were cultured in $\mathrm{f} / 2-\mathrm{Si}$ medium (Guillard, 1975) at their original salinities (Table I). 
TABLE I

List of Prorocentrum minimum strains and their origin

\begin{tabular}{llccl}
\hline Strain & Geographic origin & $\begin{array}{c}\text { Isolation } \\
\text { date }\end{array}$ & $\begin{array}{c}\text { Original } \\
\text { salinity (PSU) }\end{array}$ & Source \\
\hline MAR & Marano Lagoon, North Adriatic Sea & 2004 & 8 & $\begin{array}{l}\text { M. Monti, } \\
\text { OGS, Italy }\end{array}$ \\
RAV (PMKNA0201) & Sacca di Goro, Adriatic Sea & 2002 & 16 & $\begin{array}{l}\text { F. Guerrini, Univ. } \\
\text { Bologna, Italy }\end{array}$ \\
SWE (Swe 3) & $\begin{array}{l}\text { Baltic Sea, Sweden - } \\
\text { Himmerfjärden Bay }\end{array}$ & 2003 & 8 & $\begin{array}{l}\text { S. Pertola, FIMR, } \\
\text { Finland }\end{array}$ \\
FIN (Tve 1) & $\begin{array}{l}\text { Gulf of Finland - } \\
\text { Tvärminne Zoological Stat. }\end{array}$ & 2003 & 8 & $\begin{array}{l}\text { S. Pertola, } \\
\text { FIMR, Finland }\end{array}$ \\
\hline
\end{tabular}

A week before the experiment, all strains were transferred to $\mathrm{f} / 2-\mathrm{Si}$ media with salinities 8 and 32 PSU. For the experiment, cells were transferred to $100 \mathrm{ml}$ of the media in $250 \mathrm{ml}$ Erlenmeyer flasks to reach the final concentration of 1500 cells ml-1. The experimental cultures were grown in three replicates for each strain and salinity, under cool-white fluorescent light (12:12h light:dark cycle, average $57 \pm 2 \mu \mathrm{mol} \mathrm{m} \mathrm{m}^{-2} \mathrm{~s}^{-1}$ PAR) and temperature $19.8 \pm 0.7^{\circ} \mathrm{C}$. During the experiment, locations of individual culture flasks in the growth chamber were regularly changed at random. Samples for the measurements were collected from each flask on day 3,11 , and 19 , presumably in the three different phases of $P$. minimum growth (Monti et al., 2005).

\section{Pigment composition}

The qualitative and quantitative analysis of pigment in the samples was performed by the reverse-phase HPLC (High Performance Liquid Chromatography) method (Mantoura and Llewellyn, 1983; Barlow et al., 1993). Water samples (1 to $60 \mathrm{ml}$ ) were filtered through Whatman GF/ $\mathrm{F}$ filters and immediately frozen. Frozen samples were extracted in $4 \mathrm{ml}$ of $90 \%$ acetone, using sonication, and centrifuged for $10 \mathrm{~min}$ at 4,000 $\mathrm{rpm}$ in order to remove particles. An aliquot $(300 \mu \mathrm{l})$ of clarified extract was mixed with $300 \mu \mathrm{l} 1$ mol -1 ammonium acetate and $500 \mu \mathrm{l}$ of mixture injected in the gradient HPLC system with $200 \mu 1$ loop. The HPLC system was equipped with a reverse phase $3 \mu \mathrm{m} \mathrm{C}_{18}$ column (Pecosphere, 35x4.5 mm, Perkin Elmer). Solvent A consisted of $80 \%$ of methanol and $20 \%$ of $1 \mathrm{~mol}^{-1}$ ammonium acetate, and solvent B contained $60 \%$ of methanol and $40 \%$ of acetone. A linear gradient from $0 \% \mathrm{~B}$ to $100 \% \mathrm{~B}$ for $10 \mathrm{~min}$ was followed by an isocratic hold at $100 \%$ B for $6 \mathrm{~min}$. The rinse flow was $1 \mathrm{ml} \mathrm{min}^{-1}$. Chlorophylls and carotenoids were detected by absorbance at $440 \mathrm{~nm}$ using an $\mathrm{UV} / \mathrm{Vis}$ spectrophotometric detector (Spectra Physics, Model UV2000). Degradation products of chlorophyll $a$ were detected by measuring fluorescence $(420 / 672 \mathrm{~nm})$ with a spectrofluorimetric detector (Spectra Physics, Model FL2000). Data collection and integration were performed utilizing Agilent ChemStation software.

\section{Delayed fluorescence measurement}

DF was measured in a custom-made photon-counting luminometer (Drinovec et al., 2004). The luminometer includes an illuminator for photo-excitation $(20 \mathrm{~W}$ halogen lamp), a thermostated sample holder, and a light detector. Two filters were used for sample illumination: $<600$ $\mathrm{nm}$ filter provided light intensity of 58 
umol $\mathrm{m}^{-2} \mathrm{~s}^{-1}$ PAR at the sample position; and $>650 \mathrm{~nm}$ filter provided $30 \mu \mathrm{mol} \mathrm{m} \mathrm{m}^{-2} \mathrm{~s}^{-1}$ PAR. The sample holder for $5 \mathrm{ml}$ cuvettes was temperature-controlled to $21 \pm 0.1^{\circ} \mathrm{C}$. For light detection, a red-light-sensitive photomultiplier tube (Hamamatsu R1104) with a Hamamatsu C3866 Photon Counting Unit for signal conditioning and amplification was used, connected to a personal computer for data collection. Background noise (dark current) was measured prior to each DF measurement.

For the measurements, $2 \mathrm{ml}$ samples were adapted for 10 minutes in the dark. After $3 \mathrm{~s}$ illumination, DF was measured in the interval 1-60 $\mathrm{s}$ after the illumination pulse with a $0.1 \mathrm{~s}$ integration time.

\section{Data analysis}

The average background noise was subtracted from the DF data. DFI was calculated as the sum of measured photon counts in the first second of the measurement. The parameters of DF decay kinetics were calculated from the two decay curves measured at the two illuminations. The curves of each sample were divided, and the resulting peak was evaluated for its position and intensity.

A cluster analysis was used to analyze pigment data sets for different strains growing at different salinities (8 or 32 PSU). Dendrograms showing the level of relatedness among different strains were based on hierarchical grouping into pairs using the unweighted pair-group average method analysis of clustering (Davis, 1973). For cluster analysis, differences calculated using the Bray-Curtis coefficient were utilized (Bray and Curtis, 1957): (i) on the ratio of concentration of different carotenoid pigments to the sum of all carotenoid pigments in the samples; and (ii) on the ratio of concentration of different carotenoid pigments to the chlorophyll $a$ concentration.

The differences in DF and Chl $a$ concentrations between different strains and between individual strains growing at different salinities were statistically analyzed by means of the Student's t-test. An evaluation of the linear relationship between DFI and Chl $a$ values of individual samples was made using Pearson's correlation.

\section{RESULTS}

Delayed fluorescence intensity of $P$. minimum strains at two salinities

DFI is a measure of the living algal biomass and can thus be utilized to track algal growth. The four strains had different DFI values indicating differences in the growth under the same laboratory conditions (Fig. $1)$. The growth of individual strains was different at the two different salinities (Fig. 1). At 8 PSU, MAR already had the highest DFI of all strains after three days of growth. RAV and SWE had the lowest DFI throughout the culture growth. All strains did not reach the stationary phase. After 11 days of growth at 32 PSU, only SWE had a lower DFI value than the other strains. On the day 19, 32 PSU cultures of the Adriatic strains were already in decline (senescence), whereas the Baltic strains were still in the stationary phase. A similar difference between the Adriatic and Baltic strains has already been observed by Monti et al. (2005).

Chl a concentrations showed similar growth relations as DFI values (data not shown). At 8 PSU, MAR produced the highest Chl $a$ concentrations and RAV, the lowest. At 32 PSU, MAR had the highest Chl $a$ concentration after 3 days of growth, whereas SWE had the lowest concentrations throughout growth. Senescence of MAR and RAV was not indicated by Chl $a$ concentration values. While DFI values and Chl $a$ content can be correlated in many conditions, they can differ when a certain percentage of cells is already dead, but still contain Chl $a$ or the pigment is present in the culture medium.

Under all culture conditions, the Baltic strains had, on average, higher growth rates calculated from DFI than the Adriatic strains (Table II). At salinity 8 PSU, the growth rates were not significantly different $(p>0.05)$. There was a significant difference between the Adriatic and the 
Baltic strains at 32 PSU $(\mathrm{p}<0.05)$. The three days. MAR, RAV, and SWE had reason for the low growth rate of the MAR comparable growth rates in both salinities, strain, which yielded the highest DFI at 8 whereas FIN had a significantly higher PSU, was rapid growth during the first growth rate at 32 PSU (Table II).
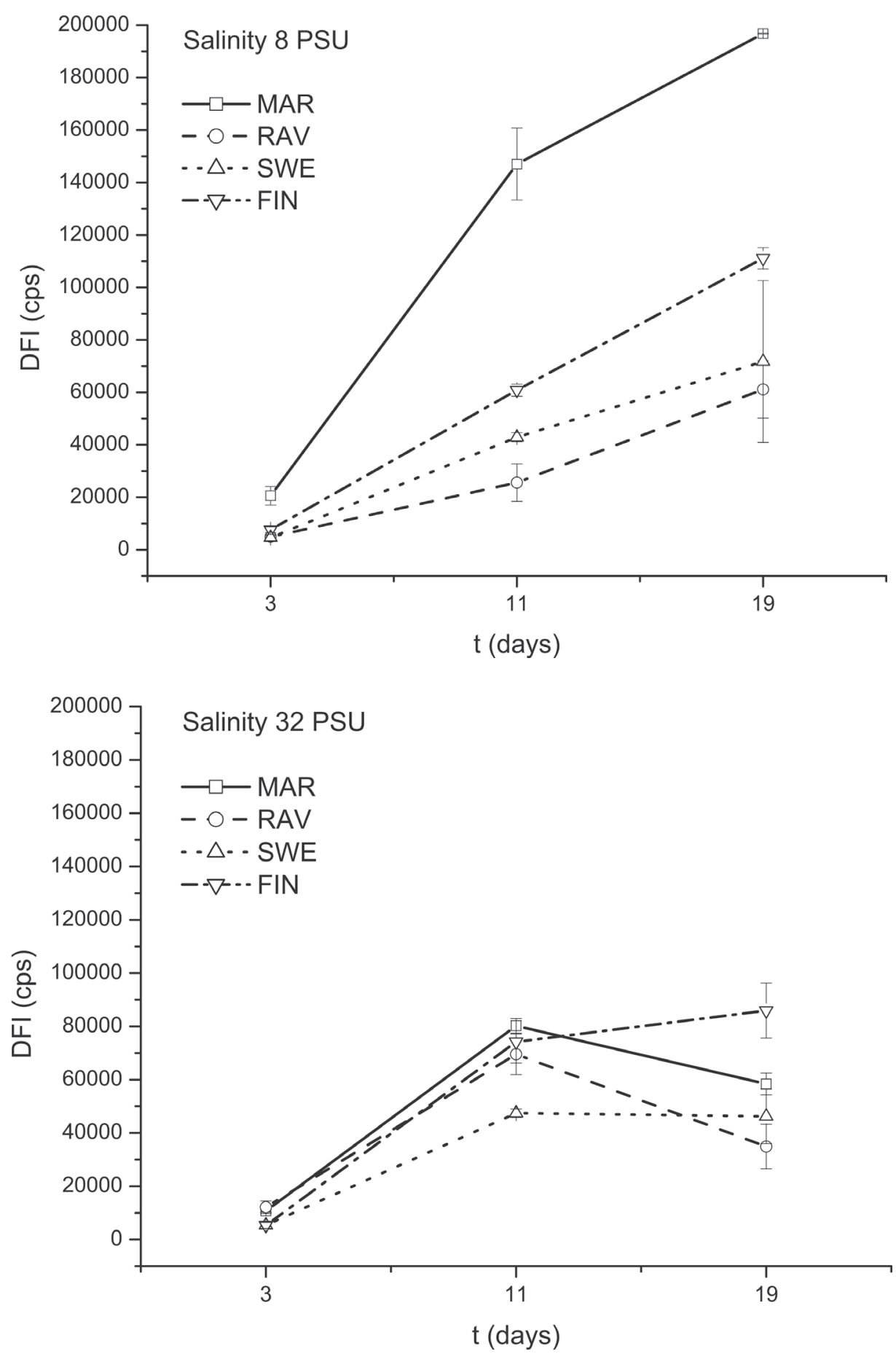

Figure 1: Delayed fluorescence intensity of four P. minimum strains growing at (a) 8 PSU and (b) 32 PSU. 
TABLE II

Growth rates of four $P$. minimum strains growing at two salinities calculated from DFI (counts per second (cps) day ${ }^{-1} ; \mathrm{N}=3$ for each strain and each exposure)

\begin{tabular}{llr}
\hline & \multicolumn{2}{c}{ Growth rate $\left(\mathrm{cps} \mathrm{day}^{-1}\right)$} \\
\cline { 2 - 3 } P. minimum strain & \multicolumn{1}{c}{ 8 PSU } & \multicolumn{1}{c}{32 PSU } \\
\hline MAR & $0.25 \pm 0.02$ & $0.25 \pm 0.003$ \\
RAV & $0.20 \pm 0.05$ & $0.22 \pm 0.03$ \\
SWE & $0.29 \pm 0.05$ & $0.27 \pm 0.01$ \\
FIN & $0.26 \pm 0.01$ & $0.33 \pm 0.04$ \\
\hline
\end{tabular}

DFI values and Chl $a$ concentrations on day 11, when all the strains were still growing, are presented in Table III for the comparison. In general, DFI values and $\mathrm{Chl}$ $a$ concentrations show a similar relationship among the strains. At 8 PSU, the MAR strain had the highest values of DFI and Chl $a$ concentration of all strains (significant at $\mathrm{p}<0.05$, Table III). The RAV strain had the lowest values in both parameters at 8 PSU. At 32 PSU, SWE had the lowest values of DFI and Chl $a$ concentration, whereas other strains did not differ significantly $(\mathrm{p}<0.05)$ (Table III). All the strains except for the SWE yielded significantly different DFI values at the two salinities $(p<0.05$, Table III), but only the Adriatic strains yielded significantly different Chl $a$ concentrations between the salinities $(\mathrm{p}<0.05$, Table III).

When Chl $a$ and DFI values were compared for individual samples (Fig. 2), they showed strong correlation $(r=0.94$, $\mathrm{p}<0.001, \mathrm{~N}=72$ ).

\section{Pigment composition}

Pigment concentrations of the samples were normalized to $\mathrm{Chl} a$ concentrations for each strain and each salinity (Tables IV-IX). Pigment concentrations on the third day were analyzed from the collective samples of all three parallels due to low pigment concentrations on that day, so there is no variation in Tables IV and V.

The cluster analysis of the pigment composition was performed to cluster the strains according to similarities and differences in pigment composition. Cluster analysis based on the ratio of individual carotenoid pigment concentrations to the chlorophyll $a$ concentration and the ratio of individual carotenoid pigment concentrations to total carotenoids were not conclusive in showing relations among the strains.

From all the analyzed pigments, only peridinin concentration ( $\mu \mathrm{g}$ peridinin per $\mu \mathrm{g}$ Chl a) on day 19 differed significantly between the salinities in all four strains (Tables VIII and IX).

\section{DF decay kinetics}

DF decay kinetics was measured at two different illumination wavelengths: $\lambda<$ $600 \mathrm{~nm}$ and $\lambda>650 \mathrm{~nm}$. The transient peak in $P$. minimum is exhibited only at longer wavelengths (Fig. 3). The DF decay curves measured after the two illuminations were divided, and the resulting peak evaluated for its position and intensity.

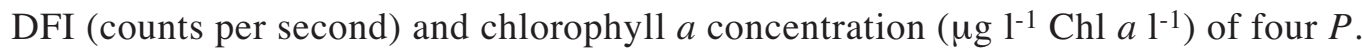
minimum strains growing at two salinities after 11 days of growth $(\mathrm{N}=3$ for each strain and each exposure)

\begin{tabular}{|c|c|c|c|c|}
\hline \multirow[b]{2}{*}{ Strain } & \multicolumn{2}{|c|}{ DFI (counts per second) } & \multicolumn{2}{|c|}{ Chlorophyll $a\left(\mu \mathrm{g} \mathrm{Chl} a 1^{-1}\right)$} \\
\hline & $8 \mathrm{PSU}$ & $32 \mathrm{PSU}$ & 8 PSU & $32 \mathrm{PSU}$ \\
\hline MAR & $147,017 \pm 13,741$ & $80,209 \pm 2,754$ & $589.4 \pm 169.9$ & $274.9 \pm 46.1$ \\
\hline RAV & $25,589 \pm 7,168$ & $69,549 \pm 7,655$ & $96.0 \pm 34.9$ & $252.3 \pm 15.1$ \\
\hline SWE & $42,903 \pm 1,719$ & $47,437 \pm 1,599$ & $224.2 \pm 107.3$ & $154.4 \pm 38.8$ \\
\hline FIN & $60,845 \pm 2,324$ & $74,192 \pm 7,912$ & $200.5 \pm 107.3$ & $276.2 \pm 77.2$ \\
\hline
\end{tabular}




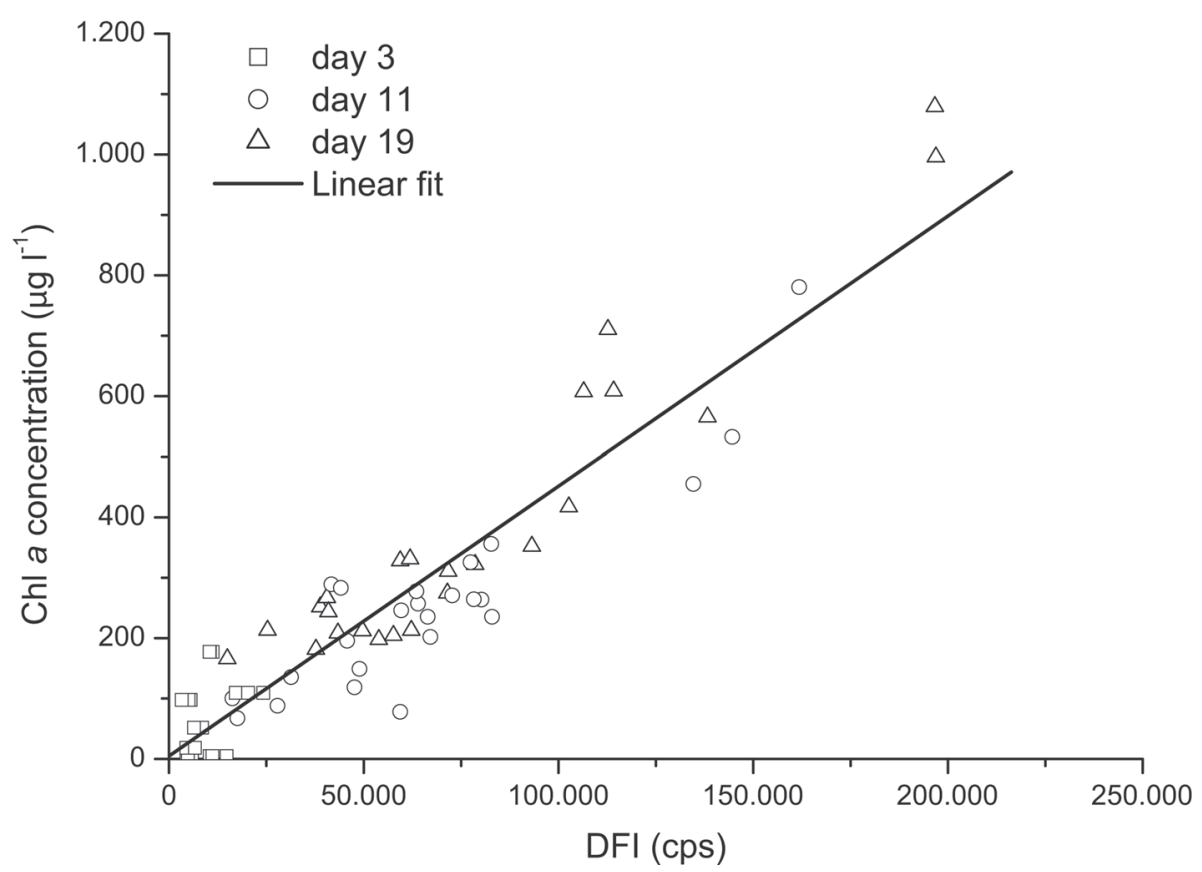

Figure 2: Comparison of Chl $a$ and DFI values for individual samples (N=72) with linear regression curve given by $\mathrm{Y}=\mathrm{A}+\mathrm{B} * \mathrm{X}: \mathrm{A}=4.8 \pm 13.8, \mathrm{~B}=0.005 \pm 0.0002$.

After three days of growth, there were no significant differences among strains' peak intensities and positions (Figs. 4 and $5)$. In general, though, peaks were more intense and delayed at the 32 PSU salinity. Between day 3 and 11, the peaks decreased in intensity in all the strains (Fig. 4). On day 11, MAR had the most intense peak of all strains at both salinities (Fig. 4). Interestingly, RAV and SWE showed many similarities in the peak intensity changes. MAR had also the most delayed peak at 32 PSU on days 11 and 19 (Fig. 5). At 8 PSU, only SWE had less delayed peak on day 11 than on day 3 and 19 (Fig. 5).

\section{DISCUSSION}

Since the early Fifties, delayed fluorescence of photosynthetic organisms has been researched under different terms like delayed luminescence or delayed light emission (Strehler and Arnold, 1951). Although difference of DF parameters among algal taxa and species has been shown, DF has not yet been researched in different strains of algal species. In studying the two previously described $P$. minimum strains from the Northern Adriatic $(\mathrm{PmK})$ and Baltic Seas (BAL), our group observed distinct differences in growth and DF decay kinetics between the two strains (Monti et al., 2005).

The four $P$. minimum strains presented here were isolated from different regions of the same geographical area as PmK and BAL (MAR and RAV - Northern Adriatic Sea, SWE and FIN - Baltic Sea). All six strains were genetically characterized and phylogenetically divided into two groups (Monti, 2007) showing the relation of strains isolated from the same geographical region. The question was if the distinction between the Adriatic and the Baltic strains could also be seen in the physiology of the four new strains, studied by means of DF and HPLC measurements.

Variation in physiological properties of strains can be in agreement with the genetic relationships found among the strains (Gómez and González, 2005). In our case, strain differences in DF decay kinetics, pigment composition and growth did not always follow their genetic relations. 
Dissimilarity in DF decay kinetics indicates difference in the physiology of photosynthesis. The faster decaying components provide information about the rate of energy absorbed by photosynthetic membranes (Desai et al., 1983). The slowly decaying components reflect the differences in the rates of back reactions in the electron chain and provide information on temporary energy storage during the photosynthetic electron transport (Desai et al., 1983).

TABLE IV

Pigment concentrations normalized to chlorophyll $a(\mathrm{Chl} a)$ concentration of four $P$. minimum strains

\begin{tabular}{cccccccc}
\hline Strain & Chl $c 3$ & Chl $c 2$ & Peridinin & Fucoxanthin & Diadinoxanthin & Alloxanthin & Diatoxanthin \\
$(\mu \mathrm{g}$ per $\mu \mathrm{g}$ & $(\mu \mathrm{g}$ per $\mu \mathrm{g}$ & $(\mu \mathrm{g}$ per $\mu \mathrm{g}$ & $(\mu \mathrm{g}$ per $\mu \mathrm{g}$ & $(\mu \mathrm{g}$ per $\mu \mathrm{g}$ & $(\mu \mathrm{g}$ per $\mu \mathrm{g}$ & $(\mu \mathrm{g}$ per $\mu \mathrm{g}$ \\
& $\mathrm{Chl} a)$ & Chl $a)$ & Chl $a)$ & Chl $a)$ & Chl $a)$ & Chl $a)$ & Chl $a)$
\end{tabular}

Day 3

$\begin{array}{llllllll}\text { MAR 8 PSU } & 0.03 & 0.55 & 0.76 & 0.06 & 0.28 & 0 & 0.02 \\ \text { RAV 8 PSU } & 0.03 & 0.64 & 0.94 & 0.09 & 0.41 & 0 & 0.03 \\ \text { SWE 8 PSU } & 0.04 & 0.58 & 0.68 & 0.10 & 0.33 & 0.003 & 0.03 \\ \text { FIN 8 PSU } & 0.04 & 0.66 & 0.76 & 0.12 & 0.34 & 0.004 & 0.04 \\ \text { MAR 32 PSU } & 0.03 & 0.58 & 0.76 & 0.06 & 0.20 & 0 & 0.01 \\ \text { RAV 32 PSU } & 0.03 & 0.42 & 0.84 & 0.09 & 0.26 & 0 & 0.02 \\ \text { SWE 32 PSU } & 0.02 & 0.56 & 0.80 & 0.07 & 0.27 & 0 & 0 \\ \text { FIN 32 PSU } & 0.04 & 0.53 & 0.85 & 0.09 & 0.33 & 0.004 & 0.03 \\ \end{array}$

Day 11

$\begin{array}{lccccccc}\text { MAR 8 PSU } & 0.03 \pm 0.004 & 0.62 \pm 0.04 & 0.89 \pm 0.07 & 0.08 \pm 0.01 & 0.38 \pm 0.05 & 0.01 \pm 0.004 & 0.03 \pm 0.004 \\ \text { RAV 8 PSU } & 0.04 \pm 0.005 & 0.77 \pm 0.07 & 1.10 \pm 0.11 & 0.11 \pm 0.01 & 0.48 \pm 0.05 & 0.002 \pm 0.004 & 0.04 \pm 0.005 \\ \text { SWE 8 PSU } & 0.03 \pm 0.004 & 0.49 \pm 0.02 & 0.81 \pm 0.11 & 0.09 \pm 0.01 & 0.41 \pm 0.08 & 0.005 \pm 0.001 & 0.04 \pm 0.005 \\ \text { FIN 8 PSU } & 0.03 \pm 0.01 & 0.57 \pm 0.03 & 0.78 \pm 0.08 & 0.08 \pm 0.03 & 0.40 \pm 0.01 & 0.008 \pm 0.004 & 0.04 \pm 0.007 \\ \text { MAR 32 PSU } & 0.03 \pm 0.002 & 0.65 \pm 0.02 & 0.96 \pm 0.07 & 0.08 \pm 0.01 & 0.33 \pm 0.01 & 0.01 \pm 0.001 & 0.02 \pm 0.007 \\ \text { RAV 32 PSU } & 0.04 \pm 0.007 & 0.75 \pm 0.08 & 1 \pm 0.09 & 0.13 \pm 0.02 & 0.45 \pm 0.04 & 0.004 \pm 0.001 & 0.04 \pm 0.01 \\ \text { SWE 32 PSU } & 0.03 \pm 0.005 & 0.53 \pm 0.06 & 0.85 \pm 0.05 & 0.09 \pm 0.007 & 0.42 \pm 0.01 & 0.001 \pm 0.001 & 0.04 \pm 0.003 \\ \text { FIN 32 PSU } & 0.03 \pm 0.004 & 0.49 \pm 0.02 & 0.81 \pm 0.11 & 0.09 \pm 0.008 & 0.41 \pm 0.08 & 0.005 \pm 0.001 & 0.04 \pm 0.005\end{array}$

Day 19

\begin{tabular}{lccccccc} 
MAR 8 PSU & $0.02 \pm 0.003$ & $0.62 \pm 0.05$ & $0.82 \pm 0.06$ & $0.09 \pm 0.02$ & $0.29 \pm 0.05$ & $0.03 \pm 0.01$ & $0.03 \pm 0.005$ \\
RAV 8 PSU & $0.04 \pm 0.006$ & $0.69 \pm 0.02$ & $0.96 \pm 0.03$ & $0.1 \pm 0.01$ & $0.34 \pm 0.01$ & $0.006 \pm 0.003$ & $0.04 \pm 0.01$ \\
SWE 8 PSU & $0.04 \pm 0.007$ & $0.65 \pm 0.04$ & $0.83 \pm 0.04$ & $0.11 \pm 0.02$ & $0.35 \pm 0.02$ & $0.01 \pm 0.01$ & $0.04 \pm 0.01$ \\
FIN 8 PSU & $0.03 \pm 0.001$ & $0.58 \pm 0.02$ & $0.73 \pm 0.01$ & $0.1 \pm 0.01$ & $0.28 \pm 0.01$ & $0.01 \pm 0.003$ & $0.03 \pm 0.01$ \\
MAR 32 PSU & $0.02 \pm 0.003$ & $0.66 \pm 0.03$ & $1.03 \pm 0.04$ & $0.06 \pm 0.01$ & $0.29 \pm 0.01$ & $0.02 \pm 0.004$ & $0.02 \pm 0.002$ \\
RAV 32 PSU & $0.03 \pm 0.004$ & $0.76 \pm 0.01$ & $1.16 \pm 0.06$ & $0.1 \pm 0.03$ & $0.36 \pm 0.005$ & $0.008 \pm 0.004$ & $0.04 \pm 0.005$ \\
SWE 32 PSU & $0.05 \pm 0.003$ & $0.83 \pm 0.01$ & $1.13 \pm 0.04$ & $0.12 \pm 0.03$ & $0.42 \pm 0.02$ & $0.002 \pm 0.002$ & $0.04 \pm 0.01$ \\
FIN 32 PSU & $0.03 \pm 0.002$ & $0.53 \pm 0.04$ & $0.83 \pm 0.06$ & $0.09 \pm 0.01$ & $0.31 \pm 0.03$ & $0.01 \pm 0.01$ & $0.03 \pm 0.006$ \\
\hline
\end{tabular}



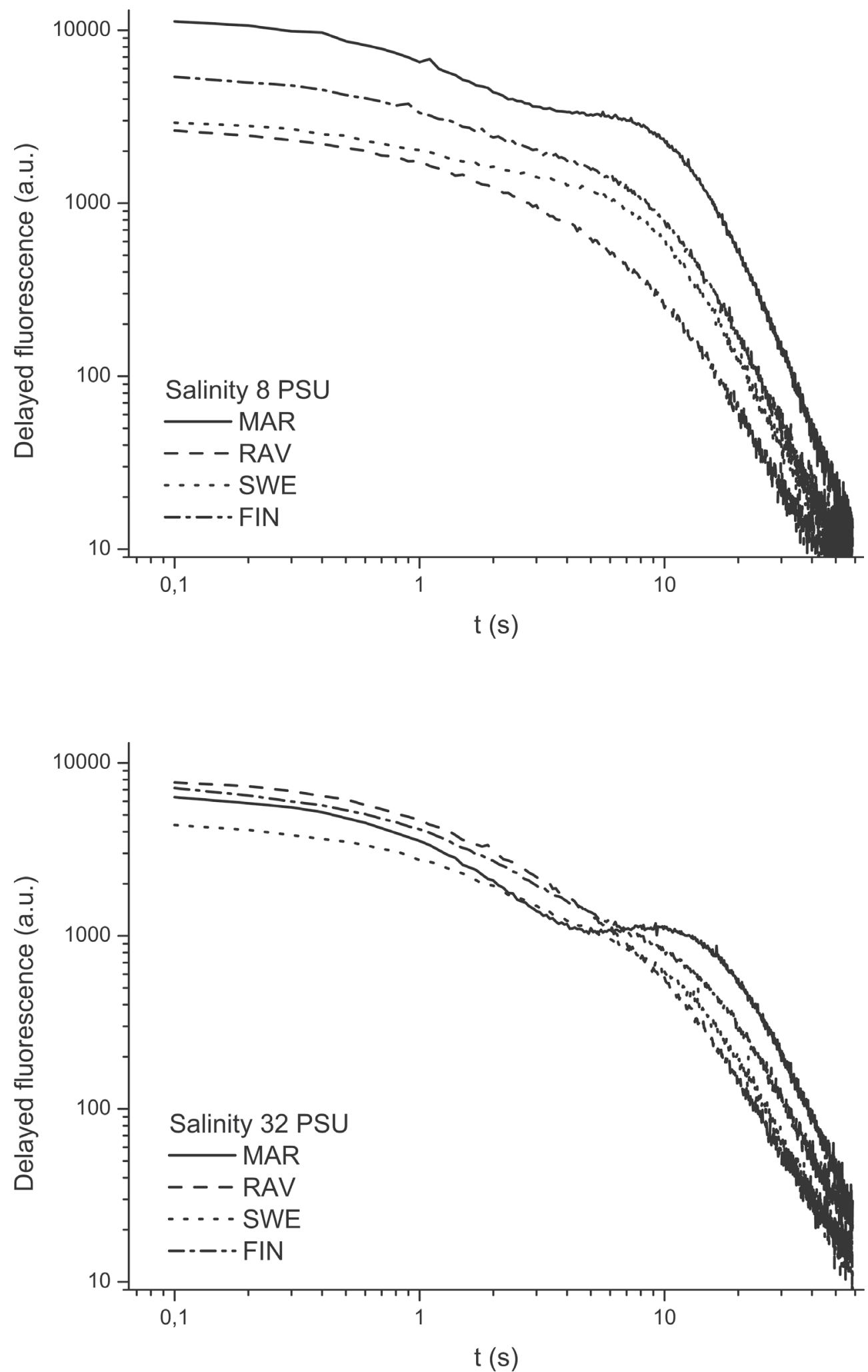

Figure 3: DF decay kinetics of four $P$. minimum strains at illumination with $\lambda>650 \mathrm{~nm}$ after 11 days of growth at salinities 8 and 32 PSU. The curves are presented in the log-log scale for better comparison. 

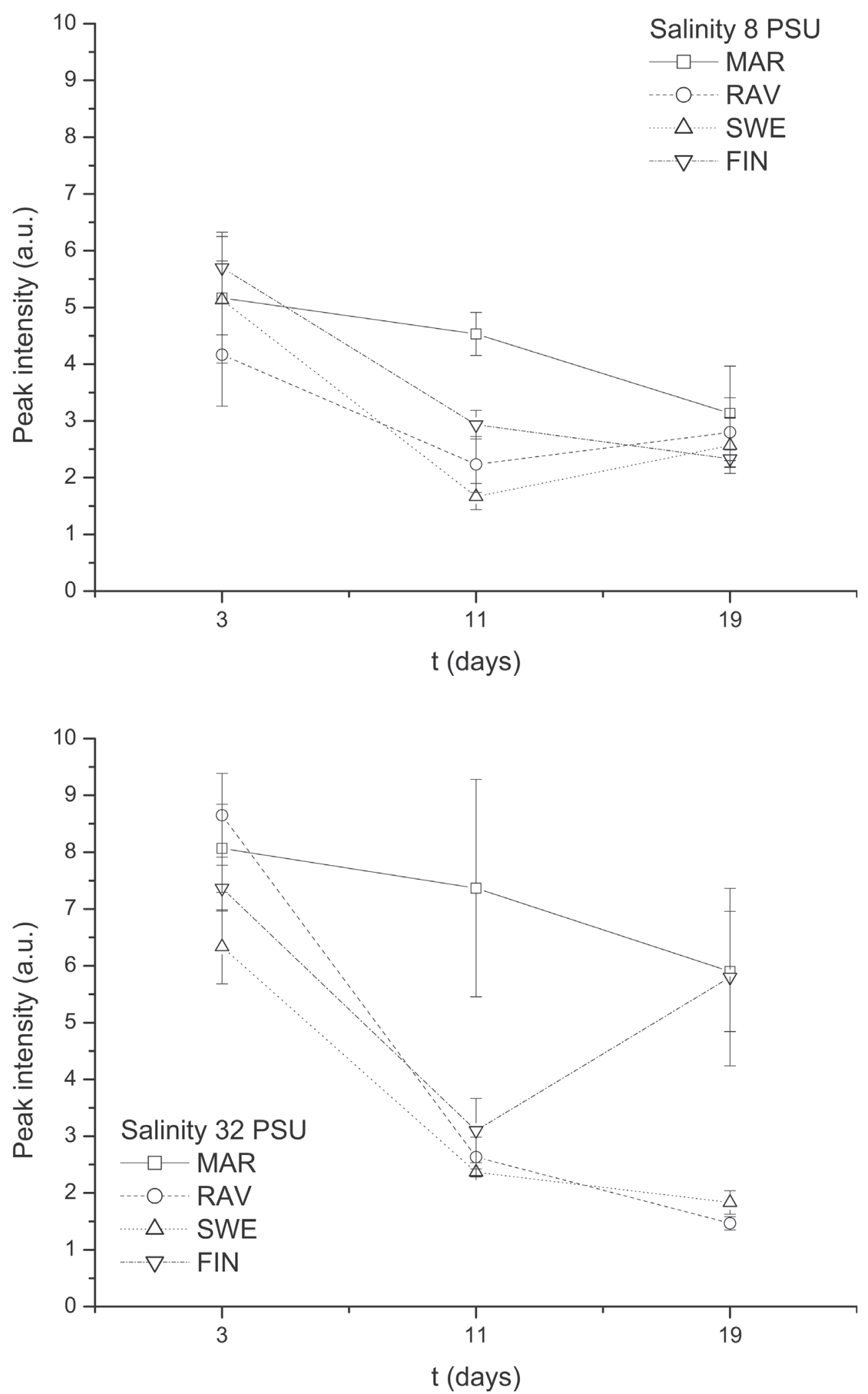

Figure 4: DF peak intensity of four P. minimum strains growing at two salinities (a) 8 PSU and (b) 32 PSU. 

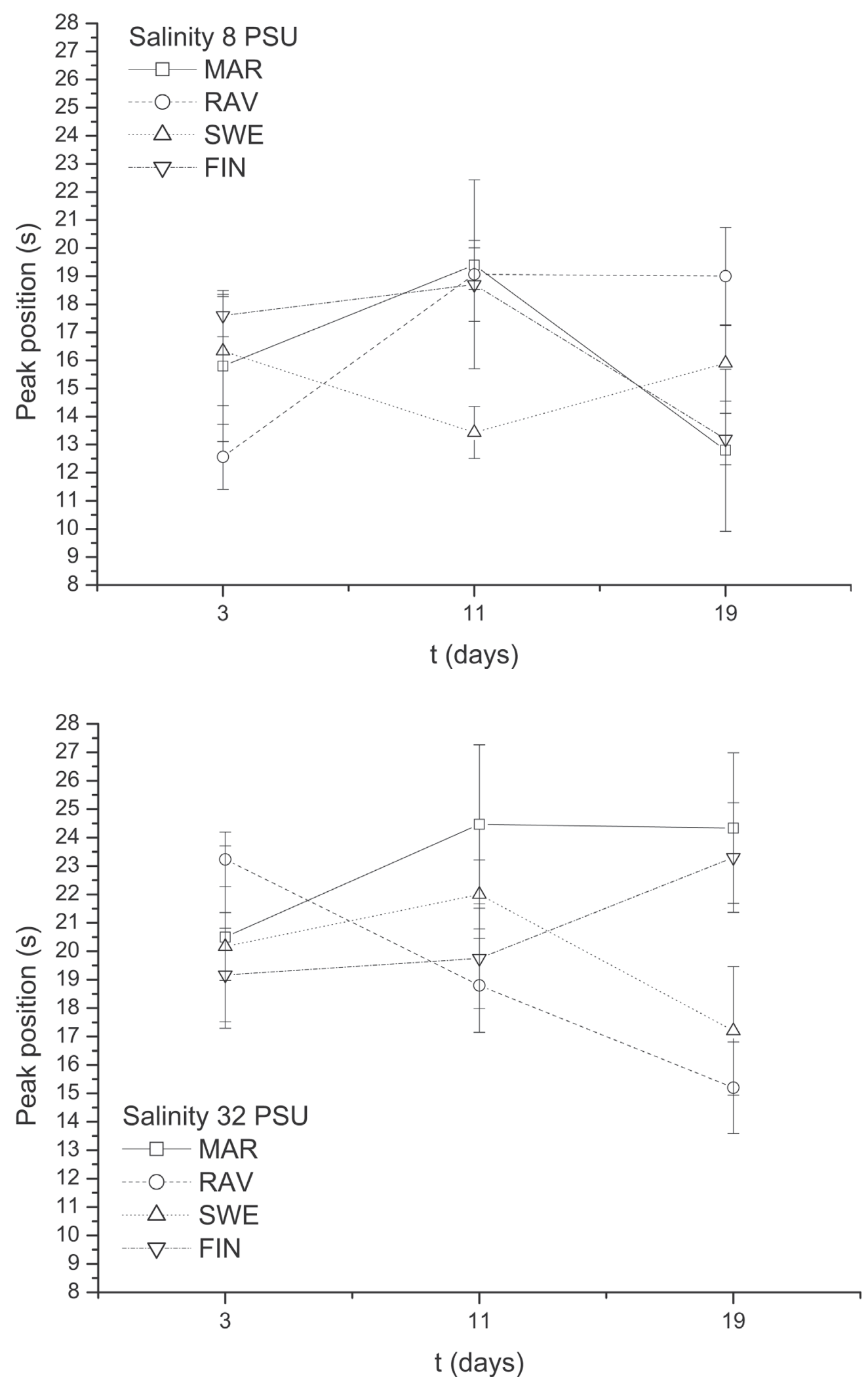

Figure 5: DF peak position of four P. minimum strains growing at two salinities (a) 8 PSU and (b) 32 PSU. 
The changes in DF peak intensity and position during growth of the FIN strain coincided with the BAL strain, both from the Baltic Sea. The same was true for the two Adriatic strains, MAR and PmK. This is an interesting feature for the Adriatic strains, because MAR and PmK grow at very different original salinities, 8 and 32 PSU, respectively. RAV, on the other hand, which grows at salinity 16 PSU, exhibited different peak parameters than PmK or MAR.

The Adriatic strains differed also in other measured parameters. The MAR strain grew better in the culture than the Baltic strains at its original salinity, which is another similarity with the PmK strain (Monti et al., 2005). After eleven days, it already had more than twice the Chl $a$ concentration and DFI at 8 PSU than the other strains at both salinities. In contrast, RAV had the lowest biomass production at the 8 PSU salinity as well as the lowest DF growth rate. The reason for slower growth of the RAV strain at 8 PSU is probably in the salinity of its natural environment, which is higher than that of the other strains. At 32 PSU, RAV exhibited DFI and Chl $a$ concentration that was comparable to the other strains at the same salinity. At a higher salinity, RAV cultures grew faster than at 8 PSU, reaching higher DFI values on day 11 and already declining at the end of the experiment. Its growth at $16 \mathrm{PSU}$ should be tested to evaluate its growth potential, but in this study we concentrated on the salinities typical for the Baltic and Northern Adriatic Seas.

Growth rates of all four strains in the two salinities were in coherence with other studies reviewed in Heil et al. (2005), where the growth rates of $P$. minimum ranged from 0.12 to $1.13 \mathrm{day}^{-1}$ under laboratory conditions. Only FIN had significantly different growth rates between the two salinities.

Cluster analysis based on the ratio of individual carotenoid pigments concentrations to the chlorophyll $a$ concentration and the ratio of individual carotenoid pigments concentrations to total carotenoids were not conclusive in showing relations among the strains. Among the measured pigments, peridinin was the only one that differed in concentrations per $\mathrm{Chl}$ $a$ between the salinities in all four strains, but only after 19 days of growth. Peridinin is an important pigment in $P$. minimum, because it is the principal photoreceptor for photosynthesis (Prezelin and Haxo, 1976). Differences in pigment contents due to the salinity have been recently shown in another potentially toxic dinoflagellate, Heterocapsa circularisquama (Leong et al., 2006) and have also been well known in the carotenoid production in Dunaliella salina (Borowitzka et al., 1990; Gómez and González, 2005).

Although the strains from the same geographical regions are phylogenetically closer to each other than to the strains isolated from other regions, they exhibit physiological differences. The differences among the strains isolated from the same region are probably a consequence of adaptations to conditions in relatively isolated areas within the region.

\section{ACKNOWLEDGEMENTS}

The work was supported by the Slovenian Research Agency (grant P1-0237). We are thankful to Sari Pertola and Franca Guerrini for the isolated strains, Milijan Šiško from Marine Biology Station Piran (NIB, Slovenia) for the cluster analysis program and Bruno Cataletto (OGS, Italy) for the useful suggestions.

\section{REFERENCES}

ARNOLD W, DAVIDSON JB (1954) The identity of the fluorescent and delayed light emission spectra in Chlorella. J Gen Physiol 37: 677-684

AVRON M, SCHREIBER U (1979) Properties of ATPinduced chlorophyll luminescence in chloroplasts. Biochim Biophys Acta 546: 448-454

BARLOW RG, MANTOURA RFC, GOUGH MA, FILEMAN TW (1993) Pigment signatures of the phytoplankton composition in the Northeastern Atlantic during the 1990 spring bloom. Deep-Sea Research Part II-Topical Studies in Oceanography 40: 459-477

BERTSCH WF (1962) Two photoreactions in photosynthesis: evidence from delayed light emission of Chlorella. Proc Natl Acad Sci USA 48: 2000-2004

BOROWITZKA MA, BOROWITZKA LJ, KESSY D (1990) Effects of salinity increase on carotenoid 
accumulation in the green alga Dunaliella salina. J Appl Phycol 2: 111-119

BRAY RJ, CURTIS TJ (1957) An ordination of the upland forest communities of Southern Wisconsin. Ecol Monogr 27: 325-349

DAVIS JC (1973) Statistics and data analysis in geology. New York: John Wiley and Sons, Inc

DENARDOU A, PUCHUS YF, VERLIST JF, BERLAND B, GRZEBYK D (1995) Toxicity of different strains of the dinoflagellate Prorocentrum minimum. Toxicon 33: 1121-1122

DENARDOU-QUENEHERVE A, GRZEBYK D, POUCHUS YF, SAUVIAT MP, ALLIOT E, BIARD JF, BERLAND B, VERBIST JF (1999) Toxicity of French strains of the dinoflagellate Prorocentrum minimum experimental and natural contaminations of mussels. Toxicon 37: 1711-1719

DESAI TS, RANE SS, TATAKE VG, SANE PV (1983) Identification of far-red-induced relative increase in the decay of delayed light-emission from photosynthetic membranes with thermo-luminescence peak-V appearing at 321-K. Biochim Biophys Acta 724: 485489

DRINOVEC L, DROBNE D, JERMAN I, ZRIMEC A (2004) Delayed fluorescence of Lemna minor: A biomarker of the effects of copper, cadmium, and zinc. Bull Environ Contam Toxicol 72: 896-902

FAUST MA, SAGER JC, MEESON BW (1982) Response of Prorocentrum mariae-lebouriae (Dinophyceae) to light of different spectral qualities and irradiances growth and pigmentation. J Phycol 18: 349-356

GÓMEZ PI, GONZÁLEZ MA (2005) The effect of temperature and irradiance on the growth and carotenogenic capacity of seven strains of Dunaliella salina (Chlorophyta) cultivated under laboratory conditions. Biol Res 38: 151-162

GRZEBYK D, BERLAND B (1996) Influence of temperature, salinity and irradiance on growth of Prorocentrum minimum (Dinophyceae) from the Mediterranean Sea. J Plankton Res 18: 1837-1849

GRZEBYK D, DENARDOU A, BERLAND B, POUCHUS YF (1997) Evidence of a new toxin in the red-tide dinoflagellate Prorocentrum minimum. J Plankton Res 19: 1111-1124

GUILLARD RRL (1975) Culture of phytoplankton for feeding marine invertebrates. In: SMITH WL, CHANLEY MH (eds) Culture of marine invertebrate animals. New York: Plenum Press. pp: 29-60

HEIL CA, GLIBERT PM, FAN CL (2005) Prorocentrum minimum (Pavillard) Schiller - A review of a harmful algal bloom species of growing worldwide importance. Harmful Algae 4: 449-470

HIDEG E, KOBAYASHI M, INABA H (1991) The far-redinduced slow component of delayed light from chloroplasts is emitted from photosystem-II - Evidence from emission-spectroscopy. Photosynth Res 29: 107112

JEFFREY SW, MANTOURA RFC (1997) Development of pigment methods for oceanography: SCOR-supported working groups and objectives. In: JEFFREY SW,
MANTOURA RFC, WRIGHT SW (eds) Phytoplankton pigments in oceanography: Guidelines to modern methods. Paris: UNESCO Publishing. pp: 19-36

JOLIOT P, JOLIOT A (1980) Dependence of delayed luminescence upon adenosine-triphosphatase activity in Chlorella. Plant Physiol 65: 691-696

JOLIOT P, JOLIOT A, BOUGES B, BARBIERI G (1971) Studies of system-II photocenters by comparative measurements of luminescence, fluorescence, and oxygen emission. Photochem Photobiol 14: 287-305

LEONG SCY, NAKAZAWA M, TAGUCHI S (2006) Physiological and optical responses of the harmful dinoflagellate Heterocapsa circularisquama to a range of salinity. Hydrobiologia 559: 149-159

MANTOURA RFC, LLEWELLYN CA (1983) The rapiddetermination of algal chlorophyll and carotenoidpigments and their breakdown products in naturalwaters by reverse-phase high-performance liquidchromatography. Anal Chim Acta 151: 297-314

MONTI M (2007) Physiology of the mixotrophic dinoflagellate Prorocentrum minimum. PhD Thesis: Universita degli Studi di Trieste. pp: 142

MONTI M, ZRIMEC A, BERAN A, BERDEN ZRIMEC M, DRINOVEC L, KOSI G, TAMBERLICH F (2005) Delayed luminescence of Prorocentrum minimum under controlled conditions. Harmful Algae 4: 643-650

PREZELIN BB, HAXO FT (1976) Purification and characterization of peridinin-chlorophyll a proteins from marine dinoflagellates Glenodinium sp. and Gonyaulax polyedra. Planta 128: 133-141

STREHLER BL, ARNOLD W (1951) Light production by green plants. J Gen Physiol 34: 809-820

TYLER MA, SELIGER HH (1981) Selection for a red tide organism: Physiological responses to the physical environment. Limnol Oceanogr 26: 310-324

VAN WIJK R, SCORDINO A, TRIGLIA A, MUSUMECI F (1999) 'Simultaneous' measurements of delayed luminescence and chloroplast organization in Acetabularia acetabulum. J Photochem Photobiol BBiology 49: 142-149

WILTSHIRE KH, HARSDORF S, SMIDT B, BLOCKER G, REUTER R, SCHROEDER F (1998) The determination of algal biomass (as chlorophyll) in suspended matter from the Elbe estuary and the German Bight: A comparison of high-performance liquid chromatography, delayed fluorescence, and prompt fluorescence methods. Journal of Experimental Marine Biology and Ecology 222: 113-131

WRAIGHT CA, CROFTS AR (1971) Delayed fluorescence and the high-energy state of chloroplasts. Eur J Biochem 19: 386-397

ZAPATA M, JEFFREY SW, WRIGHT SW, RODRÍGUEZ F, GARRIDO JL, CLEMENTSON L (2004) Photosynthetic pigments in 37 species (65 strains) of Haptophyta: Implications for oceanography and chemotaxonomy. Mar Ecol-Prog Ser 270: 83-102

ZRIMEC A, DRINOVEC L, BERDEN-ZRIMEC M (2005) Influence of chemical and physical factors on longterm delayed fluorescence in Dunaliella tertiolecta. Electromagnetic Biology and Medicine 24: 309-318. 
